\title{
ANALYSIS OF STRESS IN CIRCULAR HOLLOW SECTION BY FEA AND ANALYTICAL TECHNIQUE
}

\author{
Himanshu Dhingra ${ }^{1}$, Nitesh Karnwal ${ }^{2}$ \\ ${ }^{1}$ Research \& Development, Krishna Maruti Ltd., Haryana, India \\ ${ }^{2}$ Innovation \& Incubation Centre, Manav Rachna University, Haryana, India
}

\begin{abstract}
This study focus on stress calculation in a cantilever beam by FEA \&Analytical techniques. To know the value of maximum load bearing capacity of any particular beam this study has been generated. Structural analysis is foremost requirement in a design process. Also when we perform FEA analysis of any structure we cannot blindly trust on its result. If we don't have any past result data of that structure, it became difficult for us to know the deviation of result. For that purpose we may require analytical calculation result in order to compare result value of FEA. Hence in this study a range of load values are applied on cantilever beam by both techniques. Later graph has been plotted for different load values \& verification of results is carried out.
\end{abstract}

Keywords: Structure Analysis, CATIA, FEA and Benchmarking

\section{INTRODUCTION}

Two different approaches are used to know the stress in a cantilever beam i.e. FEA Analysis \& Analytical Analysis.

To effectively evaluate the result of FEA technique for a given problem, we have chosen a case study which can also be solved by analytical solution. Comparison of both result can provide us a benchmark relation by which we measure the effectiveness of our result. The result of analytical analysis can be used to improve the process of FEA \& by doing iteration in FEA process we may bring our result much closer to calculated value. Values calculated by analytical technique can be used as a benchmarking data.

The round tube section of steel which have crossection of $(25.4 * 1.4) \mathrm{mm} \& 250 \mathrm{~mm}$ in length is used as a beam. This beam is fixed at one end \&different load values are applied from the other end. Load value of range $40 \mathrm{~N}-200 \mathrm{~N}$ is applied at one end of beam. Maximum stress \& deflection values have been recorded by both techniques.

All the boundary conditions \& material property has used same for both the cases.

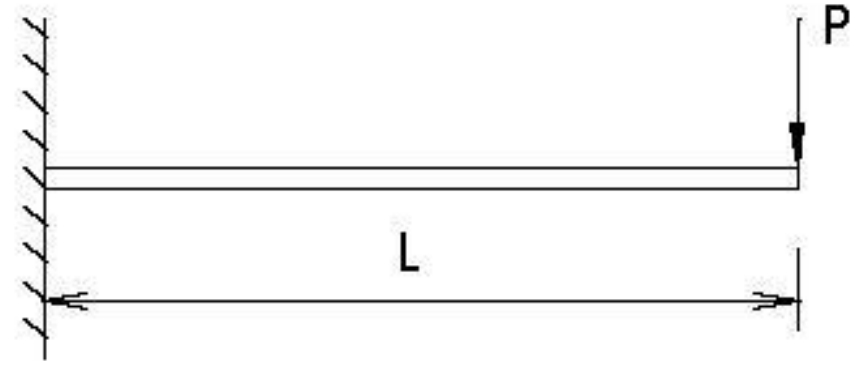

Fig-1 Overview of a cantilever beam having load applied at one end

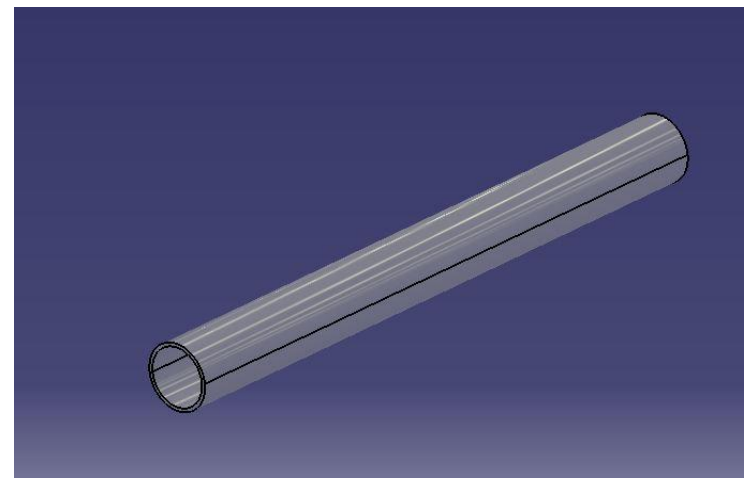

Fig 2. CAD model of circular hollow section

\section{METHODOLOGIES}

\subsection{Finite Element Analysis}

A model of round tube section with dimension of $(25.4 * 1.4 * 250) \mathrm{mm}$ has been created in CATIA software. Material property of steel such as $\mathrm{E}=2 \times 10^{\wedge} 5 \mathrm{~N} / \mathrm{mm} 2$ \& position's ratio $=0.26$ has provided to $\mathrm{CAD}$ model. After generation of CAD model it was fetch into Generative structure analysis which is a module of CATIA software. To perform the Static analysis of CAD model meshing \&boundary conditions are needed to apply as an initial step of analysis. Here we applied range values of $(40 \mathrm{~N}-200 \mathrm{~N})$ at one end by fixing other end.

Solving the computation in CATIA platform we get the result of maximum stress \& deflection which could be developing in given problem. Von Misses stress tree, which is used to show different color parameters on CAD model has highlighted maximum stress area in red color \& graph having numerical values on the stress is also provided there. Maximum amplitude of beam is also calculated by FEA which is known as maximum deflection from a given point.

The FEA result of different stress value at each load is tabulated in table no. 1 
Table-1FEA Stress \& deflection value over different load range

\begin{tabular}{|c|c|c|c|}
\hline \multicolumn{4}{|c|}{ FEA Result } \\
\hline S.No. & Total Load in (N) & Stress (in N/mm^2) & Deflection (In mm) \\
\hline 1 & 40 & 17.3 & 0.139 \\
\hline 2 & 80 & 34.6 & 0.278 \\
\hline 3 & 120 & 52 & 0.417 \\
\hline 4 & 160 & 69.3 & 0.556 \\
\hline 5 & 200 & 90.8 & 0.695 \\
\hline
\end{tabular}

Stress \& deflection value of beam under various load application has been shown in fig 3-12

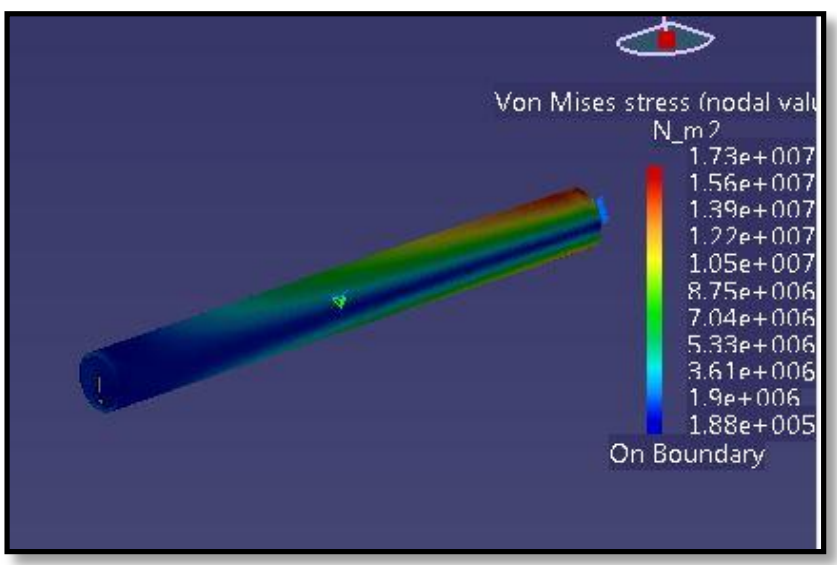

Fig-3 Stress range on a load value of $40 \mathrm{~N}$

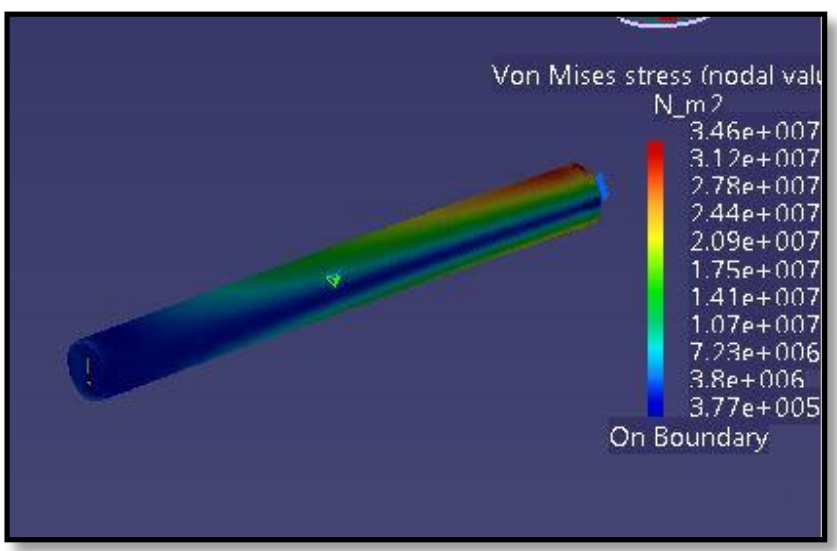

Fig-4 Stress range on a load value of $80 \mathrm{~N}$

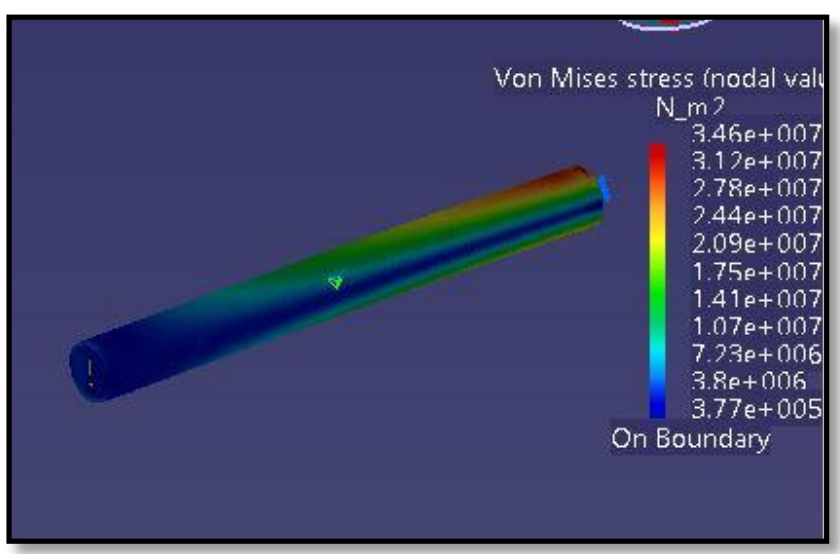

Fig-5 Stress range on a load value of $120 \mathrm{~N}$

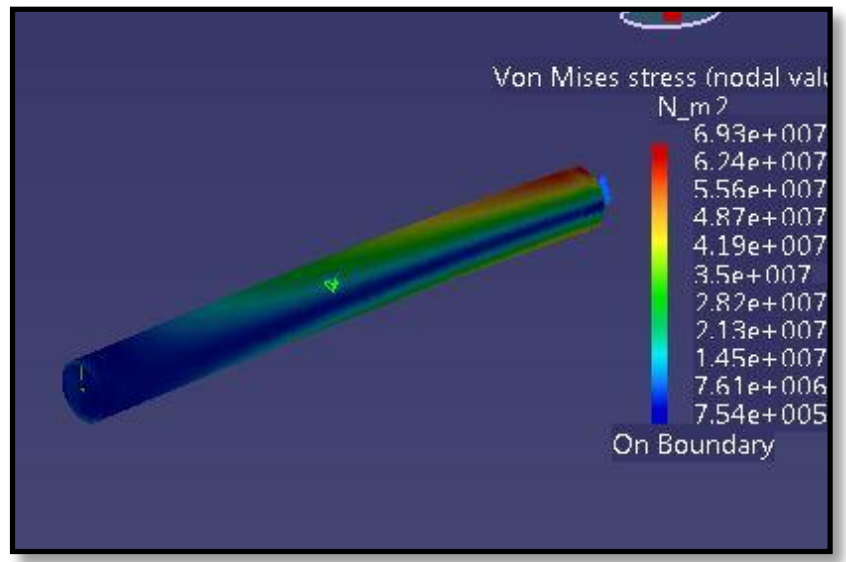

Fig-5 Stress range on a load value of $160 \mathrm{~N}$

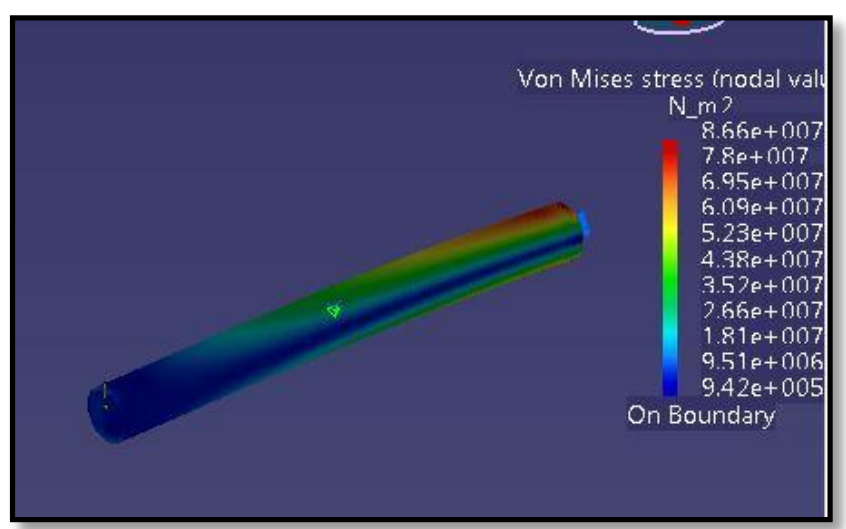

Fig-5 Stress range on a load value of $200 \mathrm{~N}$

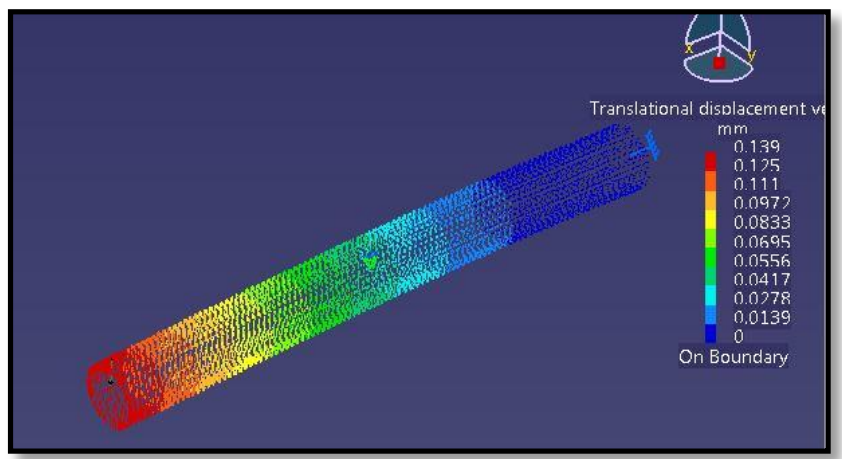

Fig-8 Deflection range on a load value of $40 \mathrm{~N}$

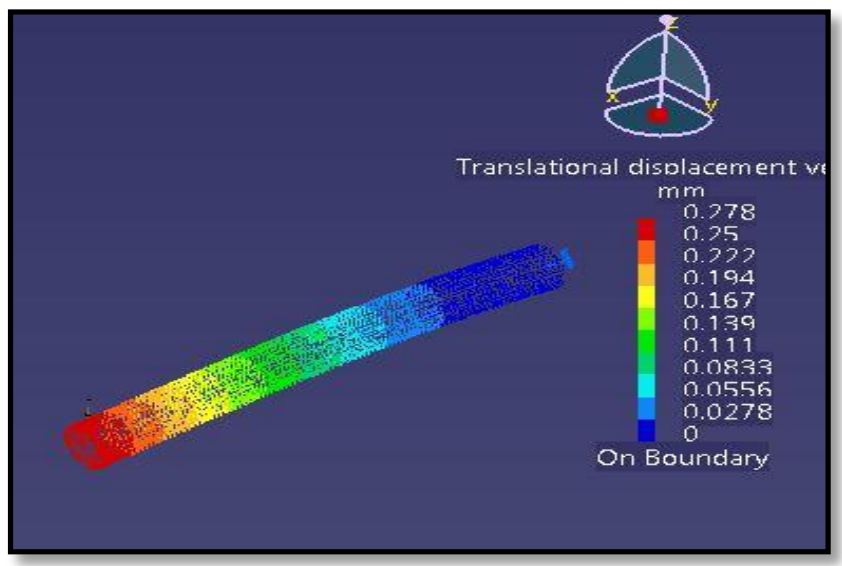

Fig-9 Deflection range on a load value of $80 \mathrm{~N}$ 


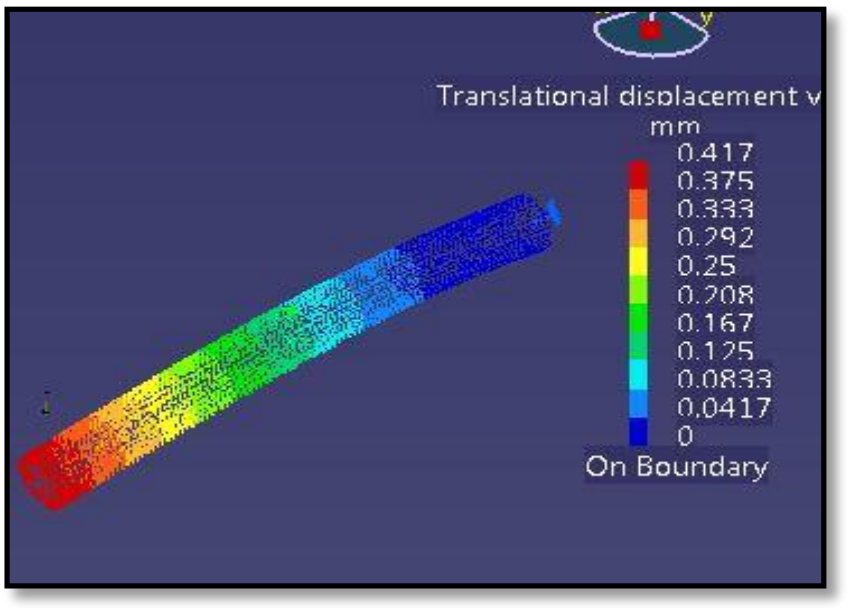

Fig-10 Deflection range on a load value of $120 \mathrm{~N}$

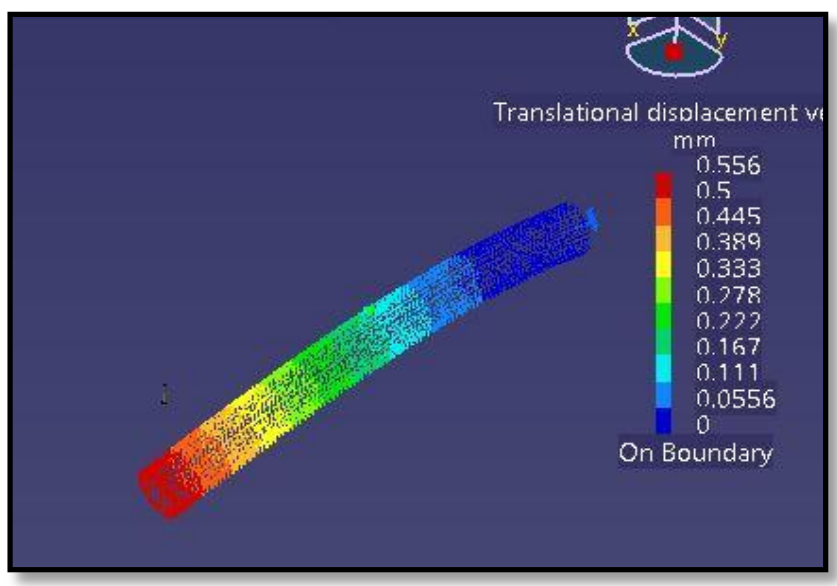

Fig-10 Deflection range on a load value of $160 \mathrm{~N}$

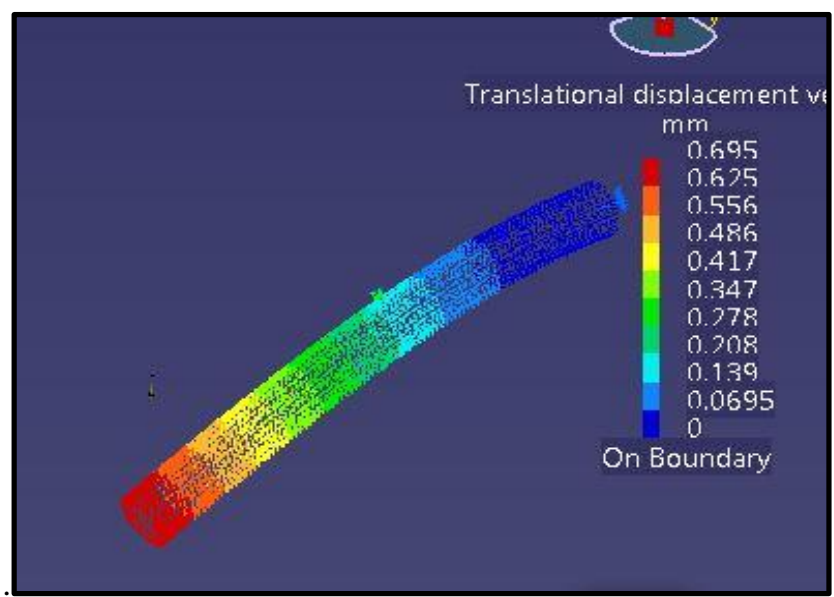

Fig-10 Deflection range on a load value of $200 \mathrm{~N}$

\subsection{Analytical Analysis}

Usually Analytical approach is used by scientists to get the result of stress \& deflection in a given problem.

Simple beam bending is often analyzed with the EulerBernoulli beam equation. The conditions for using simple bending theory are

- The beam has to obey law of pure bending.

- The material should be isotropic in nature

- Material should be in accordance with Hooke's law

- The material obeys Hooke's law (it is linearly elastic and will not deform plastically).

- The crossection of beam is to be constant throughout the length.

- The beam is initially straight with a cross section that is constant throughout the beam length.

- The beam has an axis of symmetry in the plane of bending.

For analytical analysis following equations are considered

Cross section area

Maximum bending

$$
\mathrm{A}=3.14 *\left(\mathrm{D}^{\wedge} 2\right) / 4-3.14 *\left(\mathrm{Di}^{\wedge} 2\right) / 4
$$

moment

Moment of inertia

Maximum deflection

Section Modulus

Maximum stress

$$
\begin{aligned}
& \mathrm{M}=\mathrm{P}^{*} \mathrm{~L} \\
& \mathrm{I}=3.14\left(\mathrm{D} 0^{\wedge} 2-\mathrm{Di}^{\wedge} 2\right) / 64 \\
& \mathrm{~d}=\mathrm{PL}^{\wedge} 3 /\left(3^{*} \mathrm{E}^{*} \mathrm{I}\right) \\
& \mathrm{S}=\mathrm{I} / \mathrm{Y} \\
& \mathrm{q}=\mathrm{M} / \mathrm{S}
\end{aligned}
$$

Where

$\mathrm{A}=$ Area of crossection (in $\mathrm{mm}^{\wedge} 2$ )

$\mathrm{D} 0=$ Outer diameter (in $\mathrm{mm}$ )

$\mathrm{Di}=$ Inner diameter (in $\mathrm{mm}$ )

$\mathrm{P}=$ Load applied (in N)

$\mathrm{L}=$ Length of beam (in $\mathrm{mm}$ )

$\mathrm{E}=$ Modulus of rigidity

$\mathrm{M}=$ Maximum bending moment

$\mathrm{I}=$ Moment of inertia

$\mathrm{S}=$ Section Modulus

$\mathrm{Y}=$ Neutral axis

$\mathrm{q}=$ Maximum stress

Solving the above equation we get the results listed below

$\mathrm{A}=3.14\left(25.4^{\wedge} 2\right) / 4-3.14\left(22.6^{\wedge} 2\right) / 4=105.5 \mathrm{~mm}^{\wedge} 2$

$\mathrm{M}=40 * 250=10,000$

$\mathrm{I}=3.14\left(25.4^{\wedge} 2-22.6^{\wedge} 2\right) / 64=7622.136 \mathrm{~mm}^{\wedge} 2$

Maximum deflection

$(\mathrm{d})=\left(40 * 250^{\wedge} 3\right) /(3 * 200000 * 7622.136)=0.137 \mathrm{~mm}$

Maximum stress $=10,000 /(7622.13 / 13.2)$

$$
=16.7 \mathrm{~N} / \mathrm{mm}^{\wedge} 2
$$

The same process followed for other load conditions. The analytical stress \& deflection at each load value by using above same formulation are tabulated in table no. 2

Table-2Analytical analysis of Stress \& deflection over different load range

\begin{tabular}{|c|c|c|c||}
\hline \multicolumn{4}{|c|}{ Analytical Analysis } \\
\hline S.No. & Total Load in (N) & Stress (in N/mm^2) & Deflection (In mm) \\
\hline 1 & 40 & 16.7 & 0.137 \\
\hline 2 & 80 & 33.32 & 0.273 \\
\hline 3 & 120 & 50 & 0.409 \\
\hline 4 & 160 & 66.65 & 0.546 \\
\hline 5 & 200 & 83.309 & 0.683 \\
\hline
\end{tabular}




\section{COMPARISON OF RESULTS}

For analysis purpose, the FEA stresses and deflections on cantilever beam is carried out on different values of load from the support. The comparative FEA and analytical stress results are shown in fig. $13 \&$ fig. 14 . The result in graph shows that stress \& deflection performance was similar between both techniques. The slight difference in stress value at higher loading is due to the quality of CAD model $\&$ meshing. The plot in fig $13 \&$ fig14 are good illustration of the performance of both techniques. Both of the plots are showing straight line linear relation which is also in accordance with Hook's law.

Table-4 Comparison of FEA \& Analytical result at different load condition

\begin{tabular}{||c|c|c|c|c|c||}
\hline \multirow{2}{*}{ S.No. } & \multirow{2}{*}{ Load in (N) } & \multicolumn{2}{|c|}{ FEA } & \multicolumn{2}{c|}{ Analytical } \\
\cline { 3 - 6 } & & Stress (in N/mm^2) & Deflection (In mm) & Stress (in N/mm^2) & Deflection (In mm) \\
\hline 1 & 40 & 17.3 & 0.139 & 16.7 & 0.137 \\
\hline 2 & 80 & 34.6 & 0.278 & 33.32 & 0.273 \\
\hline 3 & 120 & 52 & 0.417 & 50 & 0.409 \\
\hline 4 & 160 & 69.3 & 0.556 & 66.65 & 0.546 \\
\hline 5 & 200 & 90.8 & 0.695 & 83.309 & 0.683 \\
\hline
\end{tabular}

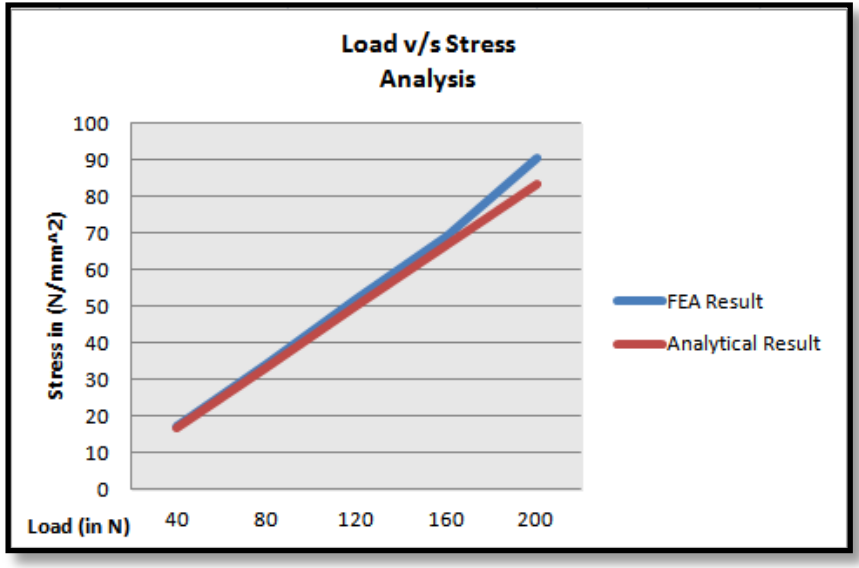

Fig-13 Load vs Stress result by both technique

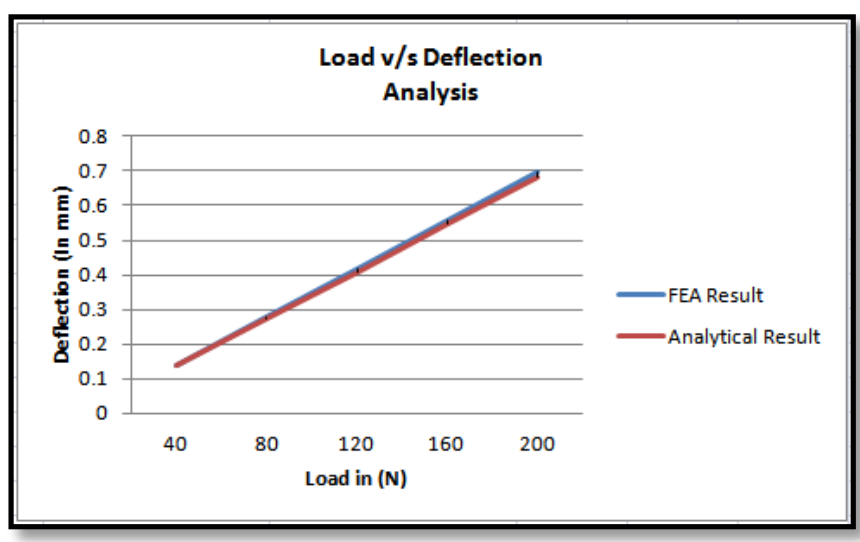

Fig-14 Load vs Deflection result by both technique

\section{CONCLUSION}

Though the complete results are presented in tabular \& graphical form, here an effort is made to evaluate the results obtained by both techniques.

From this study we have reached on a conclusion that result of FEA technique is much closer to analytical technique. The result of this case study is also in accordance with beam theory. For different sections we can used the same principle for result calculation, benchmarking of result value can be obtained for result verification which will improve the accuracy of final result.

This study is also useful for other type of sections \& for different structure.

\section{REFERENCES}

[1]. F. L. Singer, "Strength of Materials", Harper and Row Publishers, New York.

[2].Chao Ming Ching and Slamet Widodo, "Modal Testing an Analysis of cantilever Beam

[3]. Machine Design by Krumi Gupta

[4].Catia home page. Available in Internet at: http://www.3ds.com/products/catia

[5]. Catia Analysis, Cadcamlab, courseware, pdf

[6]. Strength of Material by Sadhu Singh

[7].Catiadoc.free.fr/pdf/EN-Dassault

Systems_Generative_Assembly_Structural_Analysis.pdf

[8].Wiley Online Library, Analytical method of partial differential equation

[9].Analytical method in structural engineering by Sarwaar alam Raj.

[10]. web.mae.ufl.edu/nkim/eml5526/Lect05.pdf [3].

[11]. Blogs, solidworks.com, teacher/2011/08/fea-tutorial

[12].www.academia.edu,3179335/Static_Analysis_of_Mild _Steel_Cantilever_Beam_by_Finite_Element_Modeling [13].www.learnengineering.org/2012/12/what-is-von-misesstress

[14].Meeth, Jan; Schuth, Michael Bewegungssimulation mit CATIA V5. HANSER.

[15]. web.mae.ufl.edu/nkim/eml5526/Lect05.pdf [3].

[16]. web.mae.ufl.edu/nkim/eml5526/Lect05.pdf [3]. 